\title{
ANALISIS HAMBATAN WIRAUSAHA MARTABAK DI KABUPATEN TEGAL
}

\author{
Fitra Rosadi \\ Pendidikan Ekonomi, FKIP, Universitas Pancasakti Tegal \\ FitraR123@gmail.com \\ Neni Hendaryati \\ Pendidikan Ekonomi, FKIP, Universitas Pancasakti \\ neni.pefkip@gmail.com \\ Dewi Amaliah Nafiati \\ Pendidikan Ekonomi, FKIP, Universitas Pancasakti \\ nafiatilia@gmail.com
}

\begin{abstract}
This study aims to investigate the factors inhibiting interest in entrepreneurship, especially in martabak entrepreneurs in Lebaksiu District, Tegal Regency. As the object of this research is in Lebaksiu Subdistrict which is divided into17 villages, researchers used sample three villages namely Lebaksiu Lor, Lebaksiu Kidul and Kajen. Descriptive qualitative methods is a method applied in this research. The data collection techniques used are with observation, interviews, and documentation techniques. The results showed that the inhibiting factors in martabak entrepreneurship concisted of factors originating from internal and external factors. Detected internal factors arise from within the entrepreneur martabak such as personal characteristics, experience, ability to control a business and capital factors. The second inhibiting factor is an external factor, which this factor comes from outside the private entrepreneur martabak which includes the environment, recruitment of employees who are proficient in martabak making and promotion to the mass media.
\end{abstract}

Keywords: Resistance Entrepreneur, Martabak, Tegal Regency.

\section{PENDAHULUAN}

Berwirausaha merupakan salah satu cara seseorang untuk berjuang bekerja keras dan meniti karir dalam kehidupan yang akan mendatang. Wirausaha merupakan potensi pembangunan. Pada masa sekarang sudah tidak asing lagi kita mendengar kata wirausaha (entrepreneur) dan kewirausahaan (entrepreneurship), baik dalam kegiatan bisnis, seminar, pelatihan, atau program pemberdayaan lainnya. Hal tersebut menunjukkan bahwa konsep wirausaha tidak hanya berhubungan dengan bisnis semata tetapi dikenal secara luas sehingga dapat ditemui berbagai istilah seperti penguasaha sosial (social entrepreneur), pengusaha kreatif (creative entrepreneur) dan lainnya.

Peran kewirausahaan sangat penting, antara lain mempercepat pertumbuhan ekonomi, sosial dan bisnis. Serta dapat menentukan kesuksesan suatu usaha, meningkatkan kemandirian bangsa. Selanjutnya, dalam mempercepat pembangunan daerah diperlukan satu komponen penting yaitu kewirausahaan, dimana komponen ini mendeskripsikan kegiatan yang dipenuhi dengan semangat inovasi, kreatifitas dan dinamisasi. Artinya kegiatan kewirausahaan dianggap sebagai sebuah status kualitatif yang lebih baik dibandingkan dengan status masyarakat lainnya.

Karakteristik individu, termasuk efikasi diri, pengetahuan sebelumnya dan jejaring sosial, memiliki efek signifikan terhadap pengakuan peluang wirausaha (Nikraftar and Hosseini: 2016) Geliat perekonomian yang sebagian besar dimotori oleh pengusaha sebagai wirausaha tidak hanya terjadi di kota-kota besar. Kabupaten Tegal merupakan daerah urban fringe yang turut serta berkontribusi memajukan perekonomian, terutama bidang kuliner khasnya. Beberapa kuliner khas Tegal yang sudah cukup familiar diantaranya tahu aci, sauto, olos, Martabak, kacang bogares, sate kambing dan lain-lain.

Dari beberapa makanan tersebut, Martabak merupakan salah satu makanan yang banyak digemari oleh Masyarakat. Terdapat 2 jenis Martabak khas Tegal atau dua varians martabak 
original yaitu Martabak manis yang topingnya biasanya gula, kacang, coklat, keju, dan susu serta Martabak telor yang berisi irisan daun bawang, daging cincang yang digoreng di atas penggorengan datar yang cukup lebar. Martabak Tegal tenar hingga daerah-daerah di luar Tegal, maka tak ayal lagi banyak yang serius menekuni bisnis ini. Meskipun beberapa wirausahan martabak berasal dari berbagai daerah di Tegal, namun yang terkenal dengan panganan khas ini berada di Kecamatan Lebaksiu khususnya di Desa Lebaksiu kidul, Lebaksiu lor, dan Kajen. Mayoritas masyarakat di 3 Desa tersebut terjun untuk berwirausaha Martabak yang sekarang tersebar di seluruh Indonesia.

Desa Lebaksiu lor, Lebaksiu kidul dan Kajen mayoritas penduduknya bekerja sebagai wirausaha Martabak. Jumlah wirausaha Martabak mencapai 1.844 orang dari ketiga Desa tersebut, meskipun tidak semuanya aktif. Kebanyakan dari mereka memiliki usaha Martabak sendiri dan sebagian masyarakat masih mengikuti usaha Martabak orang lain atau bisa dikatakan masih berposisi sebagai karyawan Martabak. Berikut jumlah pengusaha Martabak yang terdapat di Desa Lebaksiu Lor, Lebaksiu Kidul dan Kajen.

Berdasarkan hasil prariset yang dilakukan peneliti dengan melakukan observasi terhadap minat berwirausaha Martabak di Kecamatan Lebaksiu, Peneliti memahami ada masalah yang menghambat Masyarakat untuk berwirausaha Martabak.

Minat merupakan suatu keadaan dimana seseorang ingin melakukan sesuatu hal untuk mencapai tujuan atas kemauan sendiri. Minat muncul tidak secara mendadak tetapi muncul dikarenakan partisipasi/ keikutsertaan, pengalaman, kebiasaan, serta saat belajar dan bekerja (Susanto, Ahmad. 2016: 57). Hal ini memperlihatkan bahwa jika seseorang memiliki rasa senang yang besar dan kuat maka akan semakin besar dan kuat pula keinginan atau minat seseorang dalam melakukan sesuatu. Susanto Ahmad, (2016:57) Mengemukakan pendapat Sudirman, bahwa minat didefinisikan sebagai sebuah kondisi atau peristiwa yang muncul pada diri seseorang disaat orang tersebut dapat memaknai dan menghubungkan setiap keinginan dan kebutuhannya sendiri. Keinginan yang dimiliki berdasarkan apa yang dibutuhkan mempengaruhi dalam minat seseorang, Mahmud (2010:99) berpendapat bahwa minat adalah kecenderungan atau sebuah gairah
Akan sesuatu yang tinggi dan besar, dimana minat cukup besar pengaruhnya terhadap kualitas pembelajaran. Slameto, (2010:180) menyatakan bahwa konsep rasa suka dan teetarik terhadap sesuatu disertai dengan kesukarelaan pada faktor internal dan faktor eksternal akibat terbangunnya sebuah relasi serta tidak dalam paksaan disebut sebagai minat. Lampiran dalam keputusan menteri koperasi dan pembinaan pengusaha kecil Nomor. 961/KEP/M/XI/1995, dicantumkan bahwa:

1) Wirausaha adalah Seseorang yang memiliki semangat, sikap, perilaku, kemampuan berwirausaha dan mampu memberikan contoh atau teladan untuk masyarakat sekitar merupakan definisi seorang wirausaha.

2) Kewirausahaan adalah sifat yang dimiliki seseorang yang bersungguh-sungguh menjalankan usahanya dengan selalu mencari peluang-peluang usaha yang diwarnai dengan kegiatan inovasi dan kreatifitas baik teknologi, produk atau jasa yang baru secara efektif dan efisien sehingga menghasilkan laba dan tujuan usaha secara maksimal.

Wirausaha adalah seseorang yang mempunyai bakat dan kemampuan menciptakan kegiatah, usaha atau aktivitas bisnis dengan melihat dan menilai peluang yang ada, selalu mempunyai inovasi baru dalam produknya, berani mengambil resiko dan ketidakpastian dalam usaha untuk memperoleh keuntungan maupun meraih kesuksesan.

Berwirausaha adalah kegiatan untuk melaksanakan sutau usaha berdasarkan ide-ide kreatif dan inovatif dengan karakteristik kepribadian. Berani menghadapi tantangan, siap mental, mempunyai kepercayaan diri, berorientasi ke masa depan serta mempunyai ketrampilan untuk memenuhi kebutuhan. Minat berwirausaha adalah ketertarikan untuk melakukan kegiatan / aktifitas berwirausaha dengan melihat adanya peluang dan memanfaatkan peluang tersebut, sehingga muncul suatu usaha dan kemauan atas dasar motivasi seseorang untuk mempelajari, mencari dan berkeinginan untuk berwirausaha.

Kecenderungan mengambil risiko, kompetensi pengetahuan wirausaha, pengalaman wirausaha memiliki pengaruh terhadap efikasi diri wirausaha secara positif dan signifikan (Darmanto dan Yuliari, 2018). Alma, Buchari, (2013:24) mengutip pendapat dari Josept schumpeter yang mengatakan bahwa seorang wirausaha adalah pibadi yang mampu mengubah 
sistem perekonomian yang ada dengan karya inovatif dan kreatifitasnya baik barang dan jasa serta mampu membentuk organisasi atau lembaga yang mampu memproduksi hasil inovasi dan kreatifitasnya.

Wirausaha dituntut untuk berani mengambil resiko dan menciptakan produk inovasi yang baru untuk produknya agar diminati oleh masyarakat. Rusdiana, (2014:50) mengemukakan bahwa wirausaha adalah seseorang yang memiliki kemampuan sebagai penemu (inovator) dan juga sebagai perencana (planner). Wirauasaha merupakan sosok yang mampu menemukan dan menciptakan baik dalam bentuk produk, teknik, cara, ide, maupun organisasi untuk berusaha. Kreativitas wirausaha menunjukkan hubungan signifikan positif yang kuat dengan sikap terhadap menjadi wirausaha sosial, norma subyektif dan kontrol perilaku yang dirasakan (Tiwari dkk: 2017). Sebagai perencanaan, wirausaha berperan untuk

Merencanakan usaha, strategi, ide dan peluang, serta mampu menciptakan perusahaan atau organisasi yang baru.

Faktor internal dan faktor eksternal merupakan dua faktor yang dapat mempengaruhi tumbuhnya jiwa kewirausahaan. Adapaun faktor internal adalah faktor yang berasal dari dalam diri wirausaha itu sendiri sedangkan faktor eksternal merupakan hasil interaksi dengan lingkunganya Suryana, (2001:34). Faktor internal mengacu pada seseorang tersebut memiliki kemampuan, tujuan usaha, pengalaman dan kebebasan untuk berwirausaha, sedangkan faktor ekseternal memiliki pengaruh terhadap seseorang untuk memilih usaha dipengaruhi dukungan dari lingkungan terdekat yang akan mendorong individu untuk menjadi seorang wirausahawan.

Suryana, (2013:110) Mengemukakan pendapat dari Zimmer menyampaikan terdapat faktor kegagalan wirausaha saat menjalankan sebuah usaha yang baru, di antaranya,

a) tidak dimilikinya kompetensi manajerial serta pengetahuan dalam mengelola sebuah usaha,

b) Kurangnya pengalaman dalam berwirausaha, pengelolaan keuangan dan SDM yang belum memadai,

c) Kurangnya kemampuan untuk mengendalikan arus kas sebagai jantung dalam menjalankan kegiatan operasional usahanya,

d) Kurang cermat dalam menyusun perencanaan usaha sebagai pijakan awal dalam membangun sebuah e) pemilihan lokasi usaha yang kurang tepat sehingga sulit dalam memperkenalkan usaha barunya,

f) pengawasan terkait penggunaan alat usaha tidak dilakukan dengan baik, sehingga banyak digunakan peralatan yang tidak sesuai dengan prinsip efisien dan efektif,

g) keseriusan dalam membangun usaha baru tidak begitu dilakukan dan masih terkesan setengah hati,

h) saat terjadi peralihan atau transisi kurang mampu dikuasai dengan baik. Dari apa yang disampikan oleh Zimerer di atas, bisa dikatakan bahwa syarat seorang wirausaha dapat mencapai keberhasilan adalah jika seorang wirausaha mampu menghadapi setiap perubahan dengan semangat dan keseriusan akan usaha baru yang dibangunnya.

Dalam menjalankan sebuah bisnis terkadang resiko kegagalan dan kerugian dapat timbul karena banyaknya ketidakpastian yang terjadi dimasa yang akan datang. Sebuah usaha harus memiliki banyak cara dan strategi agar usahanya tidak mengalami kegagalan dan jauh dari resiko. Daam berwirausaha, ada beberapa faktor yang dapat memicu gagalnya usaha, diantaranya:

1) wirausaha kurang memiliki kemampuan manajerial dan lebih banyak wirausaha yang dilandaskan pada keberanian atau kurang pengalaman. Banyak orang berpendapat bahwa manajemen merupakan hal umum. Wirausaha yang tidak memiliki kemampuan pengambil keputusan yang baik, maka akan menghadirkan kegagalan pada usahanya,

2) sering wirausaha tidak fokus setelah usahanya dibuka dan dibangun yang mengakibtkan lambat laun usahanya akan berakhir atau gulung tikar. Padahal, memulai suatu bisni smembutuhkan suatu komitmen waktu dan kerja keras yang sungguh-sungguh,

3) Kontrol manajemen usaha yang tidak dijalankan dengan baik, sehingga akan berakumulasi pada permasalahan yang besar,

4). Modal yang tidak cukup, Suatu bisnis tentunya harus memiliki cukup modal untuk dapat membuka usaha dan menjalankan usaha.

\section{METODE PENELITIAN}

Penelitian ini menggunakan pendekatan deskriptif kualitatif. Desain dalam metode 
penelitian kualitatif ini berangkat dari potensi, keingintahuan di objek ada apa dan dari masalah yang bersifat sementara. Masalah tersebut berkembang setelah peneliti memasuki lapangan. Setelah melakukan penjelajahan maka peneliti baru dapat menemukan fokus penelitian. Adapu rumusan masalah dapat disusun berdasar fokus penelitian yang telah ditetapkan. Peneliti menggunakan tiga tahap yaitu:

1) Tahap pra-lapangan,

2) Tahap pekerjaan lapangan,

3) Tahap analisis data.

Sumber data dalam penelitian ini adalah data hasil observasi, rekaman video pada saat wawancara dengan pelaku usaha Matabak, catatan lapangan serta data tambahan seperti foto dan dokumen lainya. Dari data tersebut akan diperoleh berbagai macam data yang bermuara pada analisis faktor penghambat minat berwirausaha Martabak di Kecamatan Lebaksiu. wujud data dari penelitian ini adalah hasil observasi, hasil wawancara berupa catatan/ rekaman video yang dilakukan peneliti kepada para pelaku usaha, konsumen dan informan lain yang mendukung data penelitian. Selain itu wujud data dapat berupa dokumen dari kantor desa dan gambar/ foto aktivitas usaha dan aktivitas penelitian.

Pencarian keterangan/ informasi diketahui melalui lembar observasi dan pedoman wawancara yang dibuat oleh peneliti berdasarkan teori-teori ditanyakan kepada subyek penelitian, dalam hal ini pelaku usaha Martabak yang berada di tiga desa yaitu Desa Lebaksiu lor, Lebaksiu kidul, Kajen Kecamatan Lebaksiu, Kabupaten Tegal. Data yang diidentifikasi dalam penelitian ini berupa hasil observasi dan wawancara dengan pelaku usaha Martabak yang akan dianalis menggunakan analisis deskriftif kualitatif untuk mengetahui sejauh mana hambatan dalam berwirausaha Martabak sebagai data primer, sedangkan sebagai data sekunder diperoleh dari dokumentasi foto dan rekaman video.

Penelitian ini menggunakan teknik pengumpulan data dengan tiga cara yaitu:

1) observasi untuk mengamati lokasi usaha juga jarak antar usaha sejenis, latar belakang wirausaha, kemampuan mengolah Martabak, dan kemampuan melayani customer Martabak di desa Lebaksiu lor, Lebaksiu kidul, Kajen.

2) Wawancara (interview) untuk menilai keadaan seseorang, misalnya wawancara dengan pelaku wirausaha Martabak untuk mengetahui jumlah modal, upaya dalam menghadapi kompetitor, jangka waktu usaha, motivasi berwirausaha, faktor sosial, dan faktor lain yang menghambat minat berwirausaha Martabak di Desa Lebaksiu lor, Lebaksiu kidul, Kajen.

3) Dokumentasi pada penelitian ini berupa foto,dokumentasi dari Desa/termasuk dokumentasi dari Kecamatan dan rekaman video untuk memperkuat bukti penelitian dari pelaku usaha Martabak.

Penelitian ini menggunakan teknik analisis data dengan tahapan

1) data reduction (reduksi data),

2) data display (penyajian data),

3) conclusion drawing (penarikan kesimpulan).

\section{HASIL PENELITIAN DAN PEMBAHASAN}

Kecamatan Lebaksiu adalah salah satu Kecamatan yang berada di Kabupaten Tegal, tepatnya di Propinsi Jawa Tengah, Indonesia. Terletak disebelah selatan kota Slawi yang menuju kearah Purwokerto. Batas wilayah dari Kecamatan Lebaksiu sebagai berikut:

1). Sebelah utara: Kecamatan Slawi dan Kecamatan Dukuhwaru

2). Sebelah timur: Sungai kaligung yang disebelah timurnya merupakan wilayah Kecamatan Pangkah,

3). Sebelah barat: Kecamatan Pagerbarang dan Kecamatan Balapulang,

4). Sebelah selatan : Kecamatan balapulang dan Kecamatan Jatinegara.

Peneliti mengambil sampel di 3 Desa yaitu Desa Lebaksiu lor, Lebaksiu kidul dan Kajen, daerah yang mayoritas penduduknya menekuni bisnis Martabak yang tersebar diseluruh Indonesia. Pada umumnya, pebisnis Martabak menggunakan gerobag/mobil box untuk sarana transportasi penjualannya.

Hasil pengamatan yang dilakukan peneliti terhadap 9 pedagang Martabak di Desa Lebaksiu lor, Lebaksiu kidul dan Kajen. Mayoritas pedagang Martabak sudah bisa dikatakan Mahir, karena dalam membuat Martabak manis maupun Martabak telor sudah kelihatan tidak ada halangan dalam mengolahnya dan juga cepat dalam membuatnya. Lokasi dalam memilih tempat juga sudah baik yaitu berada di keramaian lalu lalang Masyarakat yang ingin berbelanja ditoko dan keperluan lain. Tempat jualan dari 9 pedagang berdekatan dengan toko Indomaret, toko Alfamart, toko Yapora, Rm. Bu 
Tomo, depan gerbang Desa Kajen, dan pasar Lebaksiu.

Berdasarkan hasil penelitian, minat berwirausaha Martabak adalah dari dirinya sendiri dan juga karena fakor keturunan keluarga. Keinginan dan kemauan berwirausaha Martabak sangat besar dimiliki oleh para pelaku usaha Martabak. Hambatan dalam berwirausaha Martabak yang paling mendasar adalah modal dan niat pada diri seseorang, sedangkan hambatan yang lainya seperti modal usaha, persaingan dalam mutu Martabak, lokasi yang kurang strategis, tidak bisa mengelola keuangan, dan juga olahan adonan Martabak maupun resep Martabak yang kurang baik menimbulkan rasa Martabak menjadi berkurang sehingga membuat jualanya tidak ramai Hambatan lainya yang dihadapi pedagang Martabak yaitu mencari karyawan yang mahir dalam membuat Martabak, cuaca yang tidak bersahabat, harga kenaikan bahan pokok Martabak, dan dari diri pedagang Martabak itu sendiri yang malas dalam berjualan Martabak.

\section{KESIMPULAN}

Berdasarakan hasil analisis data dan pembahsan yang dilakukan diperoleh kesimpulan bahwa terdapat dua faktor penghambat wirausaha martabak yaitu faktor yang berasal dari diri wirausaha itu sendiri (faktor internal) dan faktor yang berasal dari luar diri wirausaha (faktor eksternal). Faktor internal merupakan faktor yang dipicu oleh pribadi wirausaha sendiri atau individu itu sendiri, ada 3 faktor yang menghambat, diantaranya :

a) Sifat pribadi,

b) Permodalan,

c) Pengalaman dan pengendalian usaha. sedangkan untuk faktor eksternal yang dipicu dari luar pribadi wirausaha atau individu itu sendiri, ada 3 faktor yang menghambat, diantaranya :

a. Lingkungan,

b. Mencari tempat yang strategis untuk berjualan,

c. Promosi ke media massa.

\section{DAFTAR PUSTAKA}

Alma, Buchari. 2013. Kewirausahaan. Bandung: Alfabeta
Darmanto, S. dan Yuliari. G., 2018. Mediating Role of Entrepreneurial Self Efficacy In Developing Entrepreneurial Behavior of Entrepreneur Students, Academy of Entrepreneurship Journal Volume 24, Issue 1

Mahmud. 2010 Psikologi pendidikan. Bandung : CV Pustaka Setia.

Nikraftar and Hosseini. 2016. Factors affecting entrepreneurial opportunities recognition in tourism small and medium sized enterprises. TOURISM REVIEW VOL. 71 NO. 1 2016, pp. 6-17, (C) Emerald Group Publishing Limited, ISSN 1660-5373 DOI 10.1108/TR-09-2015-0042

Rusdiana. 2014. Kewirausahaan Teori dan Praktik. Bandung: Pustaka Setia.

Slameto. 2010. Belajar dan faktor-faktor yang mempengaruhi. Jakarta : Rineka Cipta.

Sugiono. 2015. Metode penelitian pendekatan kuantitatif, kualitatif, dan R\&D. Bandung : Alfabeta.

Susanto, Ahmad. 2013. Teori Belajar dan Pembelajaran di Sekolah Dasar. Jakarta: Prenadamedia Group.

Suryana. 2013. Kewirausahaan: Kiat dan Proses Menuju Sukses. Jakarta: Salemba Empat.

Tiwari et al. 2017. An empirical analysis of the factors affecting social entrepreneurial intentions. Journal of Global Entrepreneurship Research 7:9 DOI 10.1186/s40497-017-0067-1 